\title{
Ultrasonographic examination of the abdomen of the goat. I. Reticulum, rumen, omasum, abomasum and intestines
}

\author{
Braun, Ueli ; Jacquat, D ; Steininger, K
}

\begin{abstract}
This review article summarizes the ultrasonographic findings of the reticulum, rumen, omasum, abomasum and intestines of goats. Ultrasonographic examination is done on both sides with the goat in a standing position using a linear array or convex transducer with a frequency of 5.0 to $7.5 \mathrm{MHz}$. The shape, contour and motility of the reticulum are assessed; this organ appears as a crescent-shaped structure with a smooth contour immediately adjacent to the diaphragm. There are 0.8 to 2.1 reticular contractions per minute, which may be mono-, bi- and triphasic. The rumen is examined from the 8th to 12th intercostal spaces (ICSs) and flank on the left, and from the 12th ICS and flank on the right. The ruminal wall appears as a thick echoic line. The dorsal and ventral sacs of the rumen are differentiated based on the longitudinal groove, which forms an echoic notch. Differentiation of the dorsal gas cap, fibre mat and fluid layer is not always straightforward and varies among goats. The omasum is examined from the 6th to 11th ICSs on the right. Only the wall closest to the transducer can be imaged and it appears as a crescent-shaped echoic line medial to the liver. The omasal folds and the wall furthest from the transducer cannot be seen. In about two thirds of goats, active omasal motility is apparent as a transient reduction in size of several centimetres, followed by relaxation and return to its original size. There is an average of 1.1 contractions per minute. The abomasum is examined from the ventral midline and the left and right paramedian regions and can always be seen from the ventral midline. In all but a few goats the abomasum is also visible from the left and right paramedian areas. It appears as a heterogeneous, moderately echoic structure with echogenic stippling. The abomasal folds appear as prominent echoic bands in about two thirds of all goats. The small and large intestines are examined on the right from the 8th to the 12th ICSs. Loops of jejunum and ileum are seen mainly in cross-section and have a strong motility. The intestinal content is usually homogeneous and echoic and the diameter of the intestinal loops varies from 0.8 and $2.7 \mathrm{~cm}$. The spiral colon and in many cases also the caecum can be imaged. The former is recognized by its garland-like appearance brought about by the centripetal and centrifugal coils of the intestine. In the spiral colon and the caecum, only the wall closest to the transducer can be imaged because of intraluminal gas. The wall appears as a thick echoic and slightly undulating line 5.6 to $8.0 \mathrm{~cm}$ in length. Ultrasonography is an imaging technique that is very well suited for the examination of the gastrointestinal tract of goats.
\end{abstract}

DOI: https://doi.org/10.1024/0036-7281/a000441

Posted at the Zurich Open Repository and Archive, University of Zurich

ZORA URL: https://doi.org/10.5167/uzh-77061

Journal Article

Accepted Version

Originally published at: 
Braun, Ueli; Jacquat, D; Steininger, K (2013). Ultrasonographic examination of the abdomen of the goat. I. Reticulum, rumen, omasum, abomasum and intestines. Schweizer Archiv für Tierheilkunde, 155(3):173-184.

DOI: https://doi.org/10.1024/0036-7281/a000441 
1 Review: Ultrasonographic examination of the abdomen of the goat. I. Reticulum, rumen, omasum, 2 abomasum and intestines

U. Braun, D. Jacquat, K. Steininger

Department of Farm Animals, University of Zurich

\section{Summary}

This review article summarizes the ultrasonographic findings of the reticulum, rumen, omasum, abomasum and intestines of goats. Ultrasonographic examination is done on both sides with the goat in a standing position using a linear array or convex transducer with a frequency of 5.0 to $7.5 \mathrm{MHz}$. The shape, contour and motility of the reticulum are assessed; this organ appears as a crescent-shaped structure with a smooth contour immediately adjacent to the diaphragm. There are 0.8 to 2.1 reticular contractions per minute, which may be mono-, bi- and triphasic. The rumen is examined from the 8th to 12th intercostal spaces (ICSs) and flank on the left, and from the 12th ICS and flank on the right. The ruminal wall appears as a thick echoic line. The dorsal and ventral sacs of the rumen are differentiated based on the longitudinal groove, which forms an echoic notch. Differentiation of the dorsal gas cap, fibre mat and fluid layer is not always straightforward and varies among goats. The omasum is examined from the 6th to 11th ICSs on the right. Only the wall closest to the transducer can be imaged and it appears as a crescent-shaped echoic line medial to the liver. The omasal folds and the wall furthest from the transducer cannot be seen. In about two thirds of goats, active omasal motility is apparent as a transient reduction in size of several centimetres, followed by relaxation and return to its original size. There is an average of 1.1 contractions per minute. The abomasum is examined from the ventral midline and the left and right paramedian regions and can always be seen from the ventral midline. In all but a few goats the abomasum is also visible from the left and right paramedian areas. It appears as a heterogeneous, moderately echoic structure with echogenic stippling. The abomasal folds appear as prominent echoic bands in about two thirds of all goats. The small and large intestines are examined on the right from the 8th to the 12th ICSs. Loops of jejunum and ileum are seen mainly in cross-section and have a strong motility. The intestinal content is usually homogeneous and echoic and the diameter of the intestinal loops varies from 0.8 and $2.7 \mathrm{~cm}$. The spiral colon and in many cases also the caecum can be imaged. The former is recognized by its garland-like appearance brought about by the centripetal and centrifugal coils of the intestine. In the spiral colon and the caecum, only the wall closest to the transducer can be imaged because of intraluminal gas. The wall appears as a thick echoic and slightly 
undulating line 5.6 to $8.0 \mathrm{~cm}$ in length. Ultrasonography is an imaging technique that is very well suited for the examination of the gastrointestinal tract of goats.

Keywords: ultrasonography, goat, reticulum, rumen, omasum, abomasum, intestines

\section{Review: Sonographische Untersuchung des Abdomens der Ziege. I. Haube, Pansen, Psalter,}

\section{Labmagen, Darm}

In dieser Review werden die sonographischen Befunde an Haube, Pansen, Psalter, Labmagen und Darm bei Ziegen beschrieben. Die sonographische Untersuchung dieser Organe erfolgt am stehenden Tier von beiden Körperseiten aus mit einem Linear- oder Convex-Schallkopf und einer Frequenz zwischen 5.0 und 7.5 MHz. An der Haube werden Form, Kontur und Motorik beurteilt. Die Haube stellt sich als halbmondförmiges Gebilde mit gleichmässiger Kontur dar, welches dem Zwerchfell unmittelbar anliegt. Sie kontrahiert sich 0.8 bis 2.1 Mal pro Minute, wobei mono-, bi- und triphasische Kontraktionen auftreten können. Der Pansen wird links in den Interkostalräumen 8 bis 12 sowie der Flanke, rechts im 12. Interkostalraum und der Flanke untersucht. Die Pansenwand ist als dicke echogene Linie zu erkennen. Die Unterscheidung zwischen dem dorsalen und dem ventralen Pansensack ist dank der seitlichen Pansenfurche, welche als echogene Einkerbung erscheint, möglich. Die Gas-, Futter- und Flüssigphase können nicht bei jeder Ziege gleich deutlich voneinander unterschieden werden. Der Psalter wird in den Interkostalräumen 6 bis 11 der rechten Körperseite untersucht. Er stellt sich als halbkugelförmiges Organ medial der Leber dar, wobei nur die dem Schallkopf zugewandte Psalterwand zu erkennen ist. Die Psalterblätter und die dem Schallkopf abgewandte Organwand können nicht dargestellt werden. Bei zwei Dritteln aller Ziegen kann eine eigentliche Psaltermotorik beobachtet werden. Dabei verkleinert sich der Psalter um mehrere Zentimeter, um danach wieder zu erschlaffen und seine ursprüngliche Grösse anzunehmen. Die Anzahl Kontraktionen beträgt durchschnittlich 1.10 pro Minute. Der Labmagen wird in der Mittellinie des Abdomens und paramedian links und rechts davon untersucht und kann von der Mittellinie des Abdomens immer dargestellt werden. Bei fast allen Ziegen kann der Labmagen auch von links und rechts paramedian gesehen werden. Er stellt sich sonographisch als heterogene, mässig echogene Struktur mit echogener Tüpfelung dar. Bei ca. 2 Dritteln aller Ziegen sind die Labmagenfalten als prominente, echogene Streifen sehr gut erkennbar. Der Darm wird rechts in den Interkostalräumen 8 bis 12 und der Flanke untersucht. Die Darmschlingen von Jejunum und Ileum sind grösstenteils im Querschnitt darstellbar und weisen rege Motorik auf. Der Darminhalt ist meist homogen und echoreich. Der Durchmesser von Jejunum und Ileum liegt zwischen 0.8 und $2.7 \mathrm{~cm}$. Am Dickdarm können die Colonscheibe, oft auch der Blinddarm dargestellt werden. Die Colonscheibe ist an den 
girlandenartig aneinander gereihten echogenen Wölbungen erkennbar, bei denen es sich um die spiralig angeordneten Gyri centripetales und centrifugales handelt. Infolge des gasigen Darminhalts kann nur die dem Schallkopf zugewandte Darmwand gesehen werden. Auch am Blinddarm ist nur die dem Schallkopf zugewandte Wand zu erkennen. Sie stellt sich als 5.6 bis $8.0 \mathrm{~cm}$ lange, dicke, echogene und leicht gewellte Linie dar.

Die Sonographie ist hervorragend geeignet, um die oben erwähnten Organe bei der Ziege darzustellen.

Schlüsselwörter: Sonographie, Ziege, Haube, Pansen, Psalter, Labmagen, Darm

\section{Introduction}

In today's society, goats are no longer kept as only food animals, but have gained in popularity as pets. It is quite common for owners of pet goats or valuable breeding goats to expect the same diagnostic workup and sophisticated treatment that would be undertaken for a dog, cat or horse or other companion animal. In addition to clinical examination and laboratory tests, diagnostic procedures may include radiography, ultrasonography and in selected cases even computed tomography. Regardless of the procedure used, reference values obtained from healthy animals are a prerequisite for the correct interpretation of findings. Therefore, during the past few years we have conducted a number of studies in healthy Saanen goats to investigate hematological variables (Tschuor et al., 2008), computed tomographic imaging of the thorax (Ohlerth et al., 2012) and abdomen (Braun et al., 2011a,b,c), as well as ultrasonographic characteristics of the reticulum (Braun and Jacquat, 2011), rumen (Braun et al., 2011), omasum (Braun and Jacquat 2011), abomasum (Braun and Jacquat, 2012), intestines (Braun et al., 2011), liver (Braun and Steininger, 2011), spleen (Braun and Steininger, 2010) and urinary tract (Steininger and Braun, 2012). The ultrasonographic findings have been published in various international journals and the purpose of this review article was to summarize theses studies for the veterinary practitioner.

\section{Technique of abdominal ultrasonography in goats}

A linear array or convex transducer with a frequency of 5.0 to 7.5 MHZ and a real-time B-mode ultrasound machine are used to examine both sides and the ventral aspect of the abdomen of the standing, non-sedated goat. Depending on the settings, the depth of penetration of a 5.0 to $7.5 \mathrm{MHz}$ transducer varies from 3 to $10 \mathrm{~cm}$. Transducers with a higher frequency of up to $13 \mathrm{MHZ}$, and therefore a lower depth of penetration, may be used for special indications such as the detailed examination of the ruminal 
transrectally to image the pelvic organs including the uterus, urinary bladder and urethra. The hair is clipped on both sides of the body and contact gel is applied to the skin. This approach is modified if only selected regions of the abdomen are to be examined.

\section{Reticulum}

Indications for ultrasonography of the reticulum

The indications are generally the same as in cattle. They include traumatic reticuloperitonitis (which is a rare disease in goats because they have fastidious eating habits and are not usually inclined to eat sharp objects (Bostedt and Dedié, 1996; Navarre and Pugh, 2002), vagal indigestion, tumours such as mesothelioma (Krametter et al., 2004) and mechanical obstruction of the reticulum caused by foreign bodies such as ropes and other items eaten by allotriophagic goats.

\section{Technique of reticular ultrasonography}

There have been several publications on ultrasonography of the caprine reticulum (Kaske et al., 1994; Jacquat, 2010; Braun and Jacquat, 2011a). The purpose is to assess the shape, contour and motility of the organ. The reticulum is identified and then examined ultrasonographically in the cranioventral aspect of the abdomen. The motility may be recorded on video for a few minutes for later analysis. The endpoints of the examination are type, frequency, amplitude and velocity of the reticular contractions, as recently described in detail in Saanen goats (Braun and Jacquat, 2011a). The duration of the contractions and interval between them are determined using a stop watch. The amplitude of a contraction is determined by placing electronic calipers on the screen in the direction of the contraction. The velocity of the reticular contraction is calculated using the amplitude and the time required for the contraction.

\section{Ultrasonographic findings of the reticulum}

The reticulum appears as a crescent-shaped structure with an even contour immediately adjacent to the diaphragm (Fig. 1). In the sternal region, the reticulum can be seen in the midline as well as in the paramedian areas on both sides. The different layers of the reticular wall can be identified only occasionally. The same is true for the mucosal folds of the reticulum, which appear in some goats as irregular echoic projections measuring a few millimeters in length and extending into the lumen. The number of contractions per minute varies from 0.8 to 2.1 with an average of $1.41 \pm 0.31$ contractions (Braun and Jacquat 2011a). Goats have biphasic and triphasic reticular contractions with the same characteristics as those seen in cattle (Braun and Rauch, 2008) (Fig. 2). In a biphasic contraction, an incomplete primary contraction with incomplete relaxation is followed by a complete contraction with 
complete relaxation. A triphasic contraction occurs when a biphasic contraction is immediately preceded

134 by a so-called rejection contraction, which functions to transport the cud into the oesophagus.

135 Monophasic contractions (Fig. 2) are of particular interest because they have not been documented in

136 cattle. Monophasic reticular contractions are the exception and they have only been observed in sheep

137 after the oral administation of a 10\% copper sulphate solution (Tsiamitas and Brikas, 1981) and in two of

138144 cows with vagal indigestion (Braun et al., 2009b). In a study of 30 goats, biphasic contractions

139 occurred in $100 \%$ of the goats, monophasic contractions in $90 \%$ and triphasic contractions in about $7 \%$

140 (Braun and Jacquat, 2011a). It can be assumed that in goats, each rumination cycle is preceded by a

141 triphasic reticular contraction, similar to reports in cattle. The reason why triphasic contractions in goats

142 are relatively rare can be explained by the observation that goats only rarely ruminate during

143 ultrasonographic examination. Monophasic contractions usually occur irregularly between biphasic

144 contractions, but in some goats, mono- and biphasic contractions alternate. The total duration of a

145 biphasic contraction varies from 5.2 to $8.0 \mathrm{~s}$ (mean $\pm \mathrm{sd}, 6.6 \pm 0.74 \mathrm{~s}$ ), and the first contraction (2.2 to 3.4

$146 \mathrm{~s} ; 2.8 \pm 0.28 \mathrm{~s}$ ) is slightly shorter than the second (2.8 to $5.4 \mathrm{~s} ; 3.9 \pm 0.66 \mathrm{~s}$ ) (Braun and Jacquat, 2011a).

147 Monophasic contractions (2.9 to $6.0 \mathrm{~s} ; 4.3 \pm 0.81 \mathrm{~s}$ ) are significantly shorter than biphasic contractions.

148 The mean interval between two reticular contractions ranges from 29 to $85 \mathrm{~s}(45.1 \pm 12.57 \mathrm{~s})$. The first

149 contraction of a biphasic contraction has a mean amplitude of $7.0 \pm 0.92 \mathrm{~cm}$ and a velocity of $4.4 \pm 0.87$

$150 \mathrm{~cm} / \mathrm{s}$. The amplitude and velocity of the second contraction could not be measured because the reticulum

151 moved beyond the penetration depth of the ultrasound waves and thus could not be visualized

152 continuously. Monophasic contractions have a mean amplitude of $5.9 \pm 1.21 \mathrm{~cm}$ and a mean velocity of

$153 \quad 1.40 \pm 0.31 \mathrm{~cm} / \mathrm{s}$.

154

155 Rumen

156 Indications for ultrasonography of the rumen

157 Indications for ultrasonography of the rumen include acute ruminal acidosis, which is caused by

158 consumption of excessive amounts of readily fermentable carbohydrates causing liquefaction of the

159 rumen content, increase in ruminal size associated with cranial functional stenosis (failure of omasal

160 transport) and inflammatory changes of the ruminal wall caused by peritonitis. There is also a case report

161 of a goat with echoic masses on the serosal surface of the rumen that were diagnosed as mesothelioma

162 based on histological examination (Krametter et al., 2004).

163

164 Technique of ruminal ultrasonography 
The ultrasonographic examination of the rumen of Saanen goats has recently been described in detail (Jacquat, 2010; Braun et al., 2011d). The rumen is examined from the 8th to 12th intercostal spaces (ICSs) and the flank on the left side and from the 12th ICS and the flank on the right side. First, the visibility of the rumen is determined on the left and the neighbouring organs are identified. The dorsal and ventral visible margins of the rumen are determined by measuring the distance from each margin to the dorsal midline (Fig. 3), and the size of the rumen is calculated by subtracting the distance of the dorsal margin from the distance of the ventral margin. The location of the longitudinal groove is also determined by measuring its distance from the dorsal midline. The dorsal sac of the rumen extends from the dorsal visible margin of the rumen to the longitudinal groove and the ventral sac extends from the longitudinal groove to the ventral visible margin of the rumen. A transducer with a higher resolution, for instance $13 \mathrm{MHz}$, is required for the assessment of the gas, fibre mat and fluid layers of the rumen. Ruminal motility is assessed from the left flank.

\section{Ultrasonographic findings of the rumen}

On the left, most of the rumen is situated immediately adjacent to the abdominal wall, and its wall appears as a thick echoic line. Differentiation of the various compartments varies; the dorsal and ventral sacs of the rumen can usually be differentiated caudally because of the prominent longitudinal groove, which appears as an echoic notch (Fig. 4). In contrast to cattle, the anterior dorsal blind sac of the rumen is only occasionally visible in goats.

Ruminal contractions cannot be directly visualized but the changes seen in the layering of the ruminal content provide indirect evidence of ruminal motility. During a contraction, the dorsal gas cap becomes smaller and the fibre mat appears larger, but afterwards the layers resume their pre-contraction size. The rumen can normally be seen from the 9th to 12th ICSs and the flank on the left. Because of superimposition of the lungs, the rumen can only be seen in about $50 \%$ of goats in the 8th ICS. The dorsal visible margin or the rumen runs parallel to the ventrocaudal margin of the lungs from cranioventral to caudodorsal. Because of superimposition of the lungs, the largest distance between the dorsal visible margin of the rumen and the dorsal midline occurs in the 8th ICS and is 18 to $26 \mathrm{~cm}(21.4$ $\pm 2.57 \mathrm{~cm}$ ) in Saanen goats (Tab. 1, Braun et al. 2011d). This distance becomes progressively smaller caudally because there is less superimposition of the lungs, and is smallest at 7 to $14 \mathrm{~cm}(9.6 \pm 1.80 \mathrm{~cm})$ in the cranial flank. The ventral visible margin of the rumen runs from craniodorsal to caudoventral; it is closest to the dorsal midline at 27 to $42 \mathrm{~cm}(32.7 \pm 3.89 \mathrm{~cm})$ in the 8th ICS and furthest at 37 to $60 \mathrm{~cm}$ $(51.7 \pm 5.08 \mathrm{~cm})$ in the 12th ICS. The visible size of the rumen is largest at 29 to $50 \mathrm{~cm}(41.6 \pm 5.13 \mathrm{~cm})$ in the 12th ICS and becomes markedly smaller cranially because of superimposition of the lungs; it is 5 
to $22 \mathrm{~cm}(11.3 \pm 4.29 \mathrm{~cm})$ in the 8th ICS. The longitudinal groove of the rumen is always distinct; it is

199

200

201

202

203

204

205

206

207

208

209

210

211

212

213

214

215

216

217

218

219

220

221

222

223

224

225

226

227

228

229

230 furthest from the dorsal midline at 27 to $31 \mathrm{~cm}(28.3 \pm 2.31 \mathrm{~cm})$ in the 8th ICS and closest at 17 to $27 \mathrm{~cm}$ $(22.3 \pm 2.68 \mathrm{~cm})$ in the 12th ICS. The dorsal sac of the rumen is largest in the cranial flank measuring $17.4 \pm 4.43 \mathrm{~cm}$ and smallest in the 8th ICS measuring $6.8 \pm 2.02 \mathrm{~cm}$ (Tab. 1). The ventral sac of the rumen is largest in the 12th ICS at $29.1 \pm 6.03 \mathrm{~cm}$ and smallest in the 8th ICS at $2.7 \pm 1.16 \mathrm{~cm}$.

In the cranial flank, the rumen is immediately adjacent to the abdominal wall, whereas in the 8th to 12th ICSs, because of superimposition of the spleen, the rumen is displaced from the abdominal wall dorsolaterally by a distance equivalent to the thickness of the spleen.

The degree to which the dorsal gas cap, fibre mat and ventral fluid layer can be differentiated from each other varies among goats. The fibre mat occupies the most space in the rumen, followed by the fluid layer. The dorsal gas cap, which occupies the smallest space, is distinct and easily identified based on the echoic rumen wall and intense reverberation artifacts medially (Fig. 5). The fibre mat is echoic and the bordering rumen wall is heterogeneous (Fig. 6). The fluid layer is hypoechoic and the bordering rumen wall is homogeneous and smooth. The transition from the dorsal gas cap to the fibre mat is usually easy to identify ultrasonographically based on the characteristic features of the two layers, but the distinction between fibre mat and fluid layer is more difficult. At the dorsal gas cap, the rumen wall is the thinnest, measuring 0.1 to $0.4 \mathrm{~cm}$, whereas ventral to the gas cap, it measures 0.2 to $0.8 \mathrm{~cm}$. On the right, the rumen can be seen in the flank in most goats and occasionally also in the 12th ICS.

\section{Omasum}

Indications for ultrasonography of the omasum

The omasum is involved in various gastrointestinal disorders, but primary diseases of the omasum are rare. Omasal impaction and omasitis occur mainly in cattle (Dirksen, 2002; Radostits et al., 2007), but conceivably could also occur in goats. Paresis of the omasum, characterised by cessation of influx of ingesta from the reticulum and leading to anterior functional stenosis syndrome (Dirksen, 2002), is also primarily a disease of cattle. The omasum may be affected secondarily by other disease processes such as peritonitis, or by ileus, which can cause retrograde congestion of the omasum with ingesta and dilation of the organ. A goat with mesothelioma had nodular changes of the omasum (Braun et al., 2009a).

\section{Technique of omasal ultrasonography}

The ultrasonographic examination of the omasum of Saanen goats has recently been described in detail (Jacquat, 2010; Braun and Jacquat, 2011b). All intercostal spaces on the right are examined from dorsal to ventral with the transducer held parallel to the ribs to assess the omasal wall, laminae and omasal 
motility. The thickness of the wall is measured electronically using the electronic calipers. The location and size of the omasum are determined by measuring the distance between the dorsal midline and the dorsal visible limit of the omasum and the distance between the dorsal midline and the ventral visible limit of the omasum, and by subtracting the former from the latter, analogous to the measurements of the rumen. The omasum is then observed during five minutes to detect possible omasal motility.

Ultrasonographic findings of the omasum

The omasum is seen in the 8th and 9th ICSs in all but a few goats (Tab. 2), and less commonly in the 6th, 7th, 10th and 11th ICSs. In most goats, the omasum is seen in three, and occasionally in four or even five consecutive ICSs. In contrast to cattle, the omasum of goats is not immediately adjacent to the abdominal wall, but instead displaced from the abdominal wall by the liver. The omasum appears as a curved echoic line, which represents the omasal wall closest to the transducer (Fig. 7). The omasal laminae and the omasal wall furthest from the transducer cannot be seen because of the gaseous nature of the omasal content.

The dorsal limit of the omasum forms a craniodorsally convex line running from cranioventral to caudodorsal (Fig. 8) and its greatest distance from the dorsal midline is measured in the 6th ICS at 24.0 to $29.0 \mathrm{~cm}(25.9 \pm 2.39 \mathrm{~cm})$ (Braun and Jacquat, 2011b). This distance progressively decreases caudally and is smallest in the 11th ICS measuring $16.5 \mathrm{~cm}$ on average. The ventral limit of the omasum forms a slightly convex line, which runs from cranioventral to caudodorsal. For the dorsal limit, the largest and smallest distances from the dorsal midline are measured in the 6th and 11th ICS, respectively. The size of the omasum is largest in the 9th ICS $(10.2 \mathrm{~cm})$ and decreases both cranially and caudally. The omasum is the smallest in the 11th ICS at an average of $6.7 \mathrm{~cm}$.

Because of its proximity to the diaphragm, the omasum moves synchronously and passively with respiration. Active omasal motility is seen in about two thirds of goats. During a contraction, the omasum decreases in size by several centimetres and then returns to its original size. At times the contractions are so strong that the omasum disappears temporarily from the monitor screen. The number of contractions varies from 0.3 to 2.0 with a mean of 1.1 contractions per minute, and each contraction lasts 4.5 to $9.2 \mathrm{~s}$ with a mean of $6.4 \mathrm{~s}$. The interval between two contractions ranges from 28 to $52 \mathrm{~s}$ with a mean of $40.4 \mathrm{~s}$.

\section{Abomasum}

Indications for ultrasonography of the abomasum 
263 Abomasal diseases affect young as well as mature goats. Abomasal tympany is a significant problem in 264 artificially raised goats that are allowed to drink large quantities of milk or milk replacer at infrequent 265 intervals. This leads to excessive fermentation in the abomasum and severe distension of the abdomen 266 (DeBey et al., 1996; Matthews, 2009b). Pyloric obstruction by phytobezoars has been described in adult 267 goats (Bath and Berg, 1979). Abomasal emptying defects, known as functional pyloric stenosis in cattle, 268 also occur in goats (Edwards and Nevel, 2008). Abomasal impaction occurs mainly in goats that are fed forage high in indigestible fibre and are deprived of water (Linklater and Smith, 1993; Matthews, 2009b). Abomasal infestation with Haemonchus contortus and Telodorsagia circumcincta is also very common (Matthews, 2009a). Severe haemonchosis results in oedema and congestion of the abomasal mucosa and marked enlargement of the abomasal lymph nodes (Pérez et al., 2001). Retrograde congestion of the abomasum following ileus of the small intestine has been described in a goat with a phytobezoar in the duodenum (Sherman, 1981). In contrast to cattle, left and right displacement of the abomasum is extremely rare in goats (Smith and Sherman, 2009) and there is only one case described in the literature (West et al., 1983).

Technique of abomasal ultrasonography

Ultrasonography of the caprine abomasum was first described by Braun and Jacquat (2012) and is a useful technique for the assessment of the position, size and content of the stomach. The abomasum is scanned from the ventral midline and from the left and right paramedial regions, and the location of the organ and appearance of its wall, folds and contents are assessed. The visible length of the abomasum is calculated from the distances of its cranial and caudal visible limits from the caudal end of the xyphoid in the ventral midline (Fig. 9). The width of the abomasum is determined by measuring the distances from the ventral midline to the maximum left and right visible abomasal limits at the point of maximum transverse expansion using a measuring tape. The vertical dimension of the abomasum (height) is measured from the ventral midline at the level of its maximum height using the electronic calipers (Fig. $10)$.

Ultrasonographic findings of the abomasum

The abomasum appears as a heterogeneous, moderately echoic structure with echogenic stippling, similar to cattle (Fig. 11). It can always be seen from the ventral midline because it is directly adjacent to the abdominal wall in this region. In all but a few goats the abomasum is also visible from the left and right paramedian regions, but the abomasal wall itself cannot be identified. The abomasal folds appear as prominent echoic bands in about two thirds of all goats (Fig. 12). Because of superimposition of the 
small intestine, the pylorus can only very rarely be identified with certainty; it may appear as a round

297 structure with a hypoechoic lumen and an echoic torus pyloricus and pyloric folds (Fig. 13).

298 The abomasum occupies similar amounts of space on the left and right. It expands further to the left cranially and further to the right caudally. The cranial and caudal visible limits of the abomasum are -0.3

$300 \pm 2.34 \mathrm{~cm}$ and $10.3 \pm 3.08 \mathrm{~cm}$ from the xyphoid, respectively, and the visible longitudinal dimension varies from $7.0 \mathrm{~cm}$ to $15.0 \mathrm{~cm}(10.7 \pm 1.96 \mathrm{~cm})$. It should be noted that the visible length of the ultrasonographically assessed abomasum differs from its true length because of superimposition of the reticulum and rumen (see Fig. 10). The same applies to the visible height of the abomasum, which varies from 3.3 to $10.6 \mathrm{~cm}(6.7 \pm 1.79 \mathrm{~cm})$. The maximum width of the abomasum is $30.2 \pm 7.43 \mathrm{~cm}$.

\section{Intestines}

Indications for ultrasonography of the intestines

In goats as well as in cattle, the principal indication for ultrasonographic examination of the intestine is suspected ileus. With ileus the small intestine is non-motile and dilated, and in rare instances, the actual cause of ileus can be visualised. Another indication is suspected paratuberculosis because the intestinal wall of goats suffering from this disease is markedly thickened compared with healthy goats $(0.8 \pm 0.4$ vs. $6.9 \pm 1.1 \mathrm{~mm}$ ) (Tharwat et al. 2012) and the mesenteric lymph nodes, which are normally not seen sonographically, are enlarged.

Technique of intestinal ultrasonography

For the examination of the small intestine, the 8th to 12th ICSs and the flank are examined on the right from dorsal to the ventral midline with the transducer held parallel to the ribs or perpendicular to the longitudinal axis of the body as previously described in cattle (Braun, 2009a) and goats (Braun et al., 2011e). The appearance, diameter, content, wall thickness and motility are subjectively assessed and the number of intestinal loops and the presence of sections of the large intestine are recorded for each ICS and for the flank. In addition, the diameter of the intestine is measured using the electronic calipers. For the examination of the large intestine, its size is determined in the 10th to 12th ICSs and the flank on the right as described in cattle (Braun, 2009a) and goats (Braun et al., 2011e). The content, wall thickness, stratification of the wall and motility are assessed and the diameters of the spiral colon and the caecum are measured. 
The cranial part of the duodenum usually cannot be differentiated from the remaining intestinal tract, but

the descending duodenum can be clearly differentiated from other sections of the small and large intestines in the majority of goats. As described in cattle, the descending duodenum is identified by its proximity to the abdominal wall and location between the two serosal layers of the greater omentum

332 (Fig. 14). It is usually seen dorsally in the cranial flank or sometimes in the caudal ICSs and its content is homogeneously echoic. The wall thickness of the descending duodenum is 0.5 to $1.7 \mathrm{~mm}$, the diameter is 0.8 to $2.3 \mathrm{~cm}(1.3 \pm 0.37 \mathrm{~cm})$ and there are 1 to $8(3.7 \pm 2.05)$ contractions per minute (Braun et al., 2011e).

The jejunum and ileum can be seen in all goats, but they cannot be differentiated from each other. These sections of the small intestine are most commonly seen in the ventral right flank, less frequently in the ventral parts of the last ICSs and only occasionally in the dorsal flank. Loops of jejunum and ileum are mostly seen in cross-section and rarely longitudinally, and are characterised by strong motility (Fig. 15). The frequency of contractions cannot be determined because the intestines are constantly in motion. The intestinal content is usually homogeneous and echoic. The diameter of the jejunum and ileum ranges from 0.8 to $2.7 \mathrm{~cm}(1.6 \pm 0.33 \mathrm{~cm})$, but most measurements are 1.2 to $1.8 \mathrm{~cm}$ and only rarely exceed 2.5 $\mathrm{cm}$. The thickness of the walls of the jejunum and ileum is 0.8 to $2.1 \mathrm{~mm}$. Goats with paratuberculosis have thickening of the wall of the small intestine (Tharwat et al., 2012).

The large intestine can always be seen and in most goats it is also possible to image the caecum separately. These structures are most commonly seen dorsally in the right flank and sometimes ventrally and rarely (spiral of colon) or never (caecum) in the 9th to 12th ICSs. The spiral colon is easily identified by the garland-like appearance of the centripetal and centrifugal coils of the intestine (Fig. 16). The spiral colon is often located medial to the small intestine and not directly adjacent to the abdominal wall, and because of a distal acoustic shadow created by the intraluminal gas, only the wall closest to the transducer can be imaged. During the ultrasonographic assessment of the spiral colon, parts of the proximal loop are usually also seen. The thickness of the wall of the spiral colon ranges from 1.0 to 2.6 $\mathrm{mm}$ and the diameter from 0.8 to $2.0 \mathrm{~cm}(1.1 \pm 0.24 \mathrm{~cm})$. Likewise in the caecum, only the wall closest to the transducer can be imaged. The wall appears as a thick, echoic, slightly undulating line with a length of 5.6 to $8.0 \mathrm{~cm}(6.6 \pm 0.69 \mathrm{~cm})$ (Fig. 17) and a thickness of 1.8 to $4.1 \mathrm{~mm}(3.0 \pm 0.74 \mathrm{~cm})$.

\section{References}

358 See communication II. 
361 Ueli Braun, Department of Farm Animals, Winterthurerstrasse 260, CH-8057 Zürich, E-mail:

362 ubraun@vetclinics.uzh.ch; Fax: ++41 446358904

363 


\section{Legend to figures}

365 Figure 1: Ultrasonogram of the reticulum of a three-year-old Saanen goat. Ultrasonography was carried out using a 5.0 MHz convex transducer in the left paramedian of the sternal region. 1 Abdominal wall, 2 Reticulum, 3 Abomasum, Cr Cranial, Cd Caudal. (Reproduced from Braun and Jacquat, 2011a).

Figure 2: Schematic representation of reticular motility. A Biphasic reticular contraction, B Monophasic reticular contraction, C Triphasic reticular contraction, 1 Duration of the first reticular contraction, 2 Duration of the second reticular contraction, 3 Duration of the interval between the biphasic contraction and the monophasic contraction, 4 Duration of the monophasic reticular contration, 5 Amplitude of the first reticular contraction, 6 Amplitude of the monophasic reticular contraction. (Reproduced from Braun and Jacquat, 2011a).

Figure 3: Schematic representation showing how rumen measurements were made in the goats. A Dorsal sac of rumen, B Longitudinal groove, C Ventral sac of rumen, 1 Distance between the midline of the back and the dorsal margin of the rumen, 2 Distance between the midline of the back and the longitudinal groove, 3 Distance between the midline of the back and the ventral margin of the rumen, 4 Size of the rumen. (Reproduced from Braun et al., 2011d).

Figure 4: Ultrasonogram of the rumen of a three-year-old Saanen goat showing the longitudinal groove.

This view was from the 12th ICS using a 5.0 MHz convex transducer. 1 Lateral abdominal wall, 2 Dorsal sac of rumen, 3 Longitudinal groove, 4 Ventral sac of rumen, 5 Insertion of the greater omentum, Ds Dorsal, Vt Ventral. (Reproduced from Braun et al., 2011d).

Figure 5: Ultrasonogram of the rumen in the region of the gas cap in a five-year-old Saanen goat viewed from the dorsal left flank using a 5.0 MHz linear transducer. 1 Abdominal wall, 2 Rumen wall, 3 Reverberation artifacts, Ds Dorsal, Vt Ventral. (Reproduced from Braun et al., 2011d).

Figure 6: Ultrasonogram of the fibre mat of the rumen of a three-year-old Saanen goat viewed from the mid-region of the left flank using a 5.0 MHz linear transducer. 1 Abdominal wall, 2 Rumen wall, 3 Fibre mat of the ruminal contents, Ds Dorsal, Vt Ventral. (Reproduced from Braun et al., 2011d).

Figure 7: Ultrasonogram of the omasum and liver of a 5-year-old Saanen goat viewed from the 9th intercostal space with a 5.0-MHz convex transducer. The omasum appears as a curved echogenic line 
medial to the liver. 1 Abdominal wall, 2 Liver, 3 Omasum, 4 Portal vein, Ds Dorsal, Vt Ventral.

398 (Reproduced from Braun and Jacquat, 2011b)

Figure 8: Location of the omasum: The lines drawn on the goat represent the dorsal and ventral limits of the omasum from the 6th to the 11th intercostal space. These limits correspond to the mean positions of the dorsal and ventral limits of the omasum in 30 healthy goats. (Reproduced from Braun and Jacquat, 2011b).

404

Figure 9: Schematic representation of the location, length and width of the abomasum in Saanen goats. A Xyphoid, B Abomasum, 1 Distance between the cranial abomasal limit and the end of the xyphoid, 2 Distance between the caudal abomasal limit and the end of the xyphoid, 3 Visible length of the abomasum, 4 Visible width of the abomasum. (Reproduced from Braun and Jacquat, 2012).

Figure 11: Ultrasonogram of the abomasum of a five-year-old Saanen goat, viewed from the left ventral

Figure 10: Schematic representation of determination of the height and length of the abomasum in Saanen goats. A Reticulum, B Anterior dorsal blind sac of the rumen, C Dorsal sac of the rumen, D Ventral sac of the rumen, E Abomasum, 1 Visible height of the abomasum, 2 Visible length of the abomasum. (Reproduced from Braun and Jacquat, 2012).

\section{0}

Figure 12 : Ultrasonogram showing an abomasal fold in a 3.5-year-old Saanen goat, viewed from the left ventral paramedian region using a 5.0 $\mathrm{MHz}$ convex transducer. The abomasal fold is seen as echogenic, undulating structure within the abomasal contents. 1 Abdominal wall, 2 Reticulum, 3 Abomasum, 4

paramedian region using a $5.0 \mathrm{MHz}$ convex transducer. The abomasum is seen caudal to the reticulum and appears as a heterogeneous, moderately echogenic structure with multifocal echogenic foci. 1 Abdominal wall, 2 Abomasum, 3 Reticulum, Cr Cranial, Cd Caudal. (Reproduced from Braun and Jacquat, 2012).

Figure 13: Ultrasonogram showing the pylorus in a four-year-old Saanen goat, viewed from the 10th intercostal space on the right using a 5.0 MHz linear transducer. The pylorus has a heterogenous echogenic appearance and is round to oval in cross section. 1 Lateral abdominal wall, 2 Pylorus, 3 Small intestines, Ds Dorsal, Vt Ventral. (Reproduced from Braun and Jacquat, 2012). 
431 Figure 14: Ultrasonogram of the descending duodenum in the craniodorsal flank of a four-year-old 432 Saanen goat. 1 Lateral abdominal wall, 2 Descending duodenum, 3 Greater omentum, 4 Large intestine, 433 Ds Dorsal, Vt Ventral. (Reproduced from Braun et al., 2011e).

434

435 Figure 15: Ultrasonogram of the jejunum in longitudinal and cross-section in the cranioventral flank of a 436 three-year-old Saanen goat. 1 Lateral abdominal wall, 2 Jejunum, longitudinal section, 3 Jejunum, cross437 section, 4 Empty intestine, 5 Large intestine, 6 Greater omentum, Ds Dorsal, Vt Ventral. (Reproduced 438 from Braun et al., 2011e).

439

440 Figure 16: Ultrasonogram of the spiral colon in the caudodorsal flank of a three-year-old Saanen goat. 1 441 Lateral abdominal wall, 2 Greater omentum, 3 Spiral colon, Ds Dorsal, Vt Ventral, Md Medial.

442 (Reproduced from Braun et al., 2011e).

443

444 Figure 17: Ultrasonogram of the caecum in the caudodorsal flank of a three-year-old Saanen goat. 1 445 Lateral abdominal wall, 2 Greater omentum, 3 Caecum, Ds Dorsal, Vt Ventral. (Reproduced from Braun 446 et al., 2011e). 
Table 1: Results of ultrasonographic examination of the rumen in 30 Saanen goats (mean \pm sd, range, all variables in cm) (reproduced from Braun et al., 2011d).

\begin{tabular}{|c|c|c|c|c|c|c|c|}
\hline \multirow{2}{*}{$\begin{array}{l}\text { Organ } \\
\text { Structure }\end{array}$} & \multicolumn{5}{|l|}{ Intercostal space } & \multicolumn{2}{|l|}{ Flank } \\
\hline & 8 & 9 & 10 & 11 & 12 & Cranial & Caudal \\
\hline $\begin{array}{l}\text { Dorsal margin } \\
\text { of the rumen }^{1}\end{array}$ & $\begin{array}{l}21.4 \pm 2.57 \\
18.0-25.5 \\
\mathrm{n}=17\end{array}$ & $\begin{array}{c}18.5 \pm 2.48 \\
12.0-22.0 \\
n=30\end{array}$ & $\begin{array}{c}15.3 \pm 2.44 \\
10.5-20.0 \\
n=30\end{array}$ & $\begin{array}{c}12.9 \pm 1.85 \\
9.5-17.0 \\
\mathrm{n}=30\end{array}$ & $\begin{array}{c}10.0 \pm 1.44 \\
7.5-13.0 \\
n=30\end{array}$ & $\begin{array}{c}9.6 \pm 1.80 \\
7.0-14.0 \\
n=30\end{array}$ & $\begin{array}{c}12.6 \pm 4.14 \\
8.0-26.0 \\
n=30\end{array}$ \\
\hline $\begin{array}{l}\text { Ventral margin } \\
\text { of the rumen }{ }^{1}\end{array}$ & $\begin{array}{l}32.7 \pm 3.89 \\
27.0-41.5 \\
\mathrm{n}=17\end{array}$ & $\begin{array}{c}37.3 \pm 6.43 \\
26.5-49.5 \\
n=30\end{array}$ & $\begin{array}{c}43.7 \pm 7.47 \\
31.0-57.5 \\
n=30\end{array}$ & $\begin{array}{c}48.0 \pm 6.61 \\
33.0-57.5 \\
n=30\end{array}$ & $\begin{array}{c}51.7 \pm 5.72 \\
37.0-60.0 \\
n=30\end{array}$ & $\begin{array}{c}51.2 \pm 5.08 \\
40.5-58.0 \\
n=30\end{array}$ & $\begin{array}{c}47.9 \pm 6.27 \\
33.0-61.0 \\
n=30\end{array}$ \\
\hline $\begin{array}{l}\text { Size of the } \\
\text { rumen }\end{array}$ & $\begin{array}{c}11.3 \pm 4.29 \\
5.0-22.0 \\
n=17\end{array}$ & $\begin{array}{c}18.9 \pm 7.49 \\
6.5-32.0 \\
n=30\end{array}$ & $\begin{array}{c}28.4 \pm 7.72 \\
15.0-41.0 \\
n=30\end{array}$ & $\begin{array}{c}35.2 \pm 6.79 \\
18.5-45.5 \\
n=30\end{array}$ & $\begin{array}{c}41.6 \pm 5.13 \\
29.0-50.0 \\
n=30\end{array}$ & $\begin{array}{c}40.9 \pm 7.41 \\
10.5-50.0 \\
n=30\end{array}$ & $\begin{array}{c}35.3 \pm 8.35 \\
16.0-46.5 \\
n=30\end{array}$ \\
\hline $\begin{array}{l}\text { Longitudinal } \\
\text { groove of the } \\
\text { rumen }{ }^{1}\end{array}$ & $\begin{array}{c}28.3 \pm 2.31 \\
27.0-31.0 \\
n=3\end{array}$ & $\begin{array}{c}27.6 \pm 2.90 \\
23.0-33.0 \\
n=17\end{array}$ & $\begin{array}{c}26.3 \pm 3.65 \\
21.0-35.0 \\
n=29\end{array}$ & $\begin{array}{c}24.1 \pm 3.02 \\
19.0-30.5 \\
n=30\end{array}$ & $\begin{array}{c}22.3 \pm 2.68 \\
17.0-26.5 \\
n=30\end{array}$ & $\begin{array}{c}27.4 \pm 4.63 \\
18.5-38.0 \\
n=30\end{array}$ & $\begin{array}{c}27.7 \pm 3.35 \\
22.0-35.0 \\
n=30\end{array}$ \\
\hline $\begin{array}{l}\text { Size of the } \\
\text { dorsal ruminal } \\
\text { sac }\end{array}$ & $\begin{array}{c}6.8 \pm 2.02 \\
5.0-9.0 \\
n=3\end{array}$ & $\begin{array}{c}9.9 \pm 2.32 \\
7.0-15.0 \\
n=19\end{array}$ & $\begin{array}{c}11.1 \pm 3.37 \\
6.0-18.5 \\
n=29\end{array}$ & $\begin{array}{c}11.2 \pm 2.69 \\
5.0-17.5 \\
n=30\end{array}$ & $\begin{array}{c}12.2 \pm 2.27 \\
7.0-16.0 \\
n=30\end{array}$ & $\begin{array}{c}17.4 \pm 4.43 \\
9.5-25.0 \\
n=30\end{array}$ & $\begin{array}{c}15.1 \pm 3.98 \\
7.5-25.0 \\
n=30\end{array}$ \\
\hline $\begin{array}{l}\text { Size of the } \\
\text { ventral ruminal } \\
\text { sac }\end{array}$ & $\begin{array}{c}2.7 \pm 1.16 \\
2.0-4.0 \\
n=3\end{array}$ & $\begin{array}{c}10.9 \pm 7.04 \\
1.0-24.0 \\
n=19\end{array}$ & $\begin{array}{c}17.8 \pm 8.01 \\
4.5-29.5 \\
n=29\end{array}$ & $\begin{array}{c}24.2 \pm 7.29 \\
8.0-34.5 \\
n=30\end{array}$ & $\begin{array}{c}29.1 \pm 6.03 \\
16.5-39.0 \\
n=30\end{array}$ & $\begin{array}{c}24.2 \pm 5.03 \\
13.5-35.0 \\
n=30\end{array}$ & $\begin{array}{c}20.5 \pm 7.08 \\
7.0-32.0 \\
n=30\end{array}$ \\
\hline $\begin{array}{l}\text { Distance from } \\
\text { the abdominal }\end{array}$ & $\begin{array}{c}1.27 \pm 1.28 \\
0.0-3.4\end{array}$ & $\begin{array}{c}2.36 \pm 1.23 \\
0.0-4.0\end{array}$ & $\begin{array}{c}2.85 \pm 0.84 \\
1.4-4.8\end{array}$ & $\begin{array}{c}2.53 \pm 0.75 \\
1.3-3.8\end{array}$ & $\begin{array}{c}1.95 \pm 0.77 \\
0.0-2.9\end{array}$ & $\begin{array}{c}0.01 \pm 0.03 \\
0.0-0.2\end{array}$ & $\begin{array}{c}0.04 \pm 0.10 \\
0.0-0.5\end{array}$ \\
\hline
\end{tabular}




$$
\mathrm{n}=11
$$

$\mathrm{n}=23$

$\mathrm{n}=23$

$\mathrm{n}=23$

$\mathrm{n}=23$

$\mathrm{n}=30$

$\mathrm{n}=30$

${ }^{1}$ Centimetres from midline of the back 
Table 2: Results of ultrasonographic examination of the omasum of 30 Saanen goats (reproduced from Braun and Jacquat, 2011b).

\begin{tabular}{|c|c|c|c|c|}
\hline Variable & $\begin{array}{c}\text { ICS } \\
\text { (No. of goats) }\end{array}$ & Mean & SD & Variation \\
\hline \multirow[t]{6}{*}{ Dorsal visible limit ${ }^{*}$} & $6(4)$ & 25.9 & 2.39 & $24.0-29.0$ \\
\hline & 7 (16) & 23.2 & 2.69 & $20.0-29.0$ \\
\hline & 8 (29) & 20.1 & 2.64 & $16.0-28.0$ \\
\hline & $9(30)$ & 17.8 & 2.46 & $13.0-24.0$ \\
\hline & $10(24)$ & 16.9 & 3.47 & $10.0-25.0$ \\
\hline & $11(3)$ & 16.5 & 4.44 & $1.5-20.0$ \\
\hline \multirow[t]{6}{*}{ Ventral visible limit ${ }^{*}$} & $6(5)$ & 33.6 & 2.88 & $29.0-36.0$ \\
\hline & $7(16)$ & 30.8 & 5.13 & $23.5-41.0$ \\
\hline & $8(29)$ & 29.0 & 3.79 & $23.0-39.0$ \\
\hline & $9(30)$ & 27.9 & 3.54 & $22.0-37.0$ \\
\hline & $10(23)$ & 25.5 & 4.59 & $18.0-36.0$ \\
\hline & $11(3)$ & 22.7 & 4.65 & $17.5-26.5$ \\
\hline \multirow[t]{6}{*}{ Size $(\mathrm{cm})$} & $\begin{array}{ll}6 & (4)\end{array}$ & 8.9 & 2.59 & $6.5-12.0$ \\
\hline & 7 (16) & 7.1 & 4.82 & $3.0-21.0$ \\
\hline & $8(29)$ & 9.2 & 3.26 & $5.0-18.0$ \\
\hline & $9(30)$ & 10.2 & 3.14 & $5.0-20.0$ \\
\hline & $10(24)$ & 8.5 & 2.55 & $5.0-15.0$ \\
\hline & $11(4)$ & 6.7 & 1.30 & $6.0-9.0$ \\
\hline
\end{tabular}

ICS = Intercostal space

* Centimetres from midline of the back 


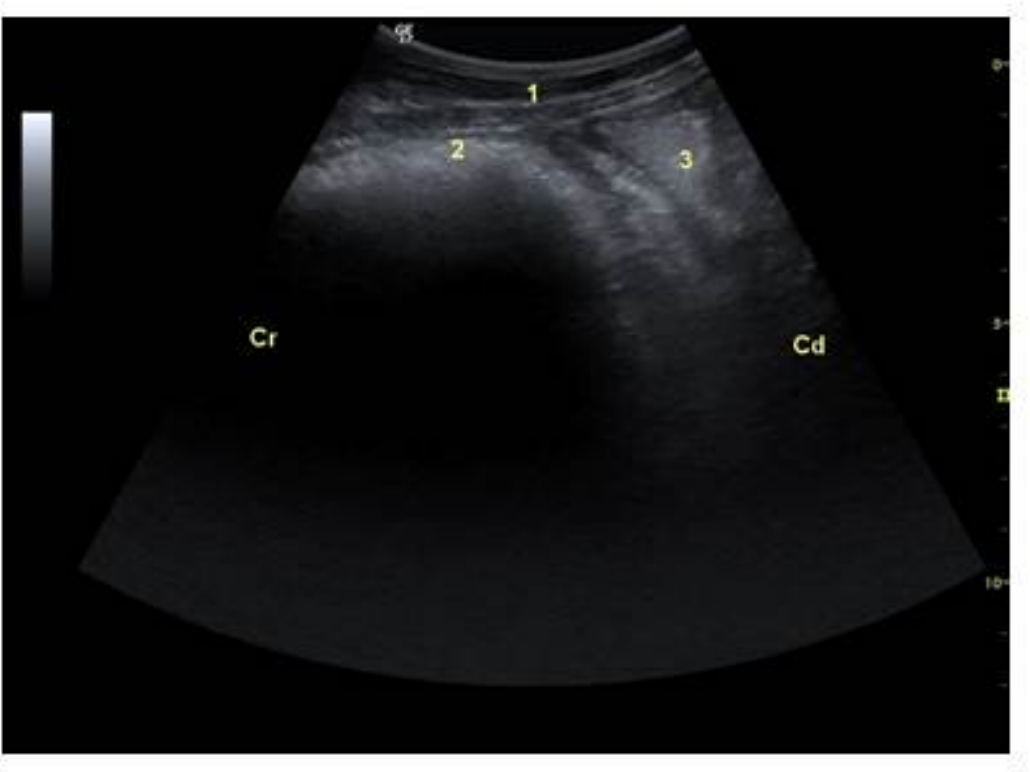

Figure 1

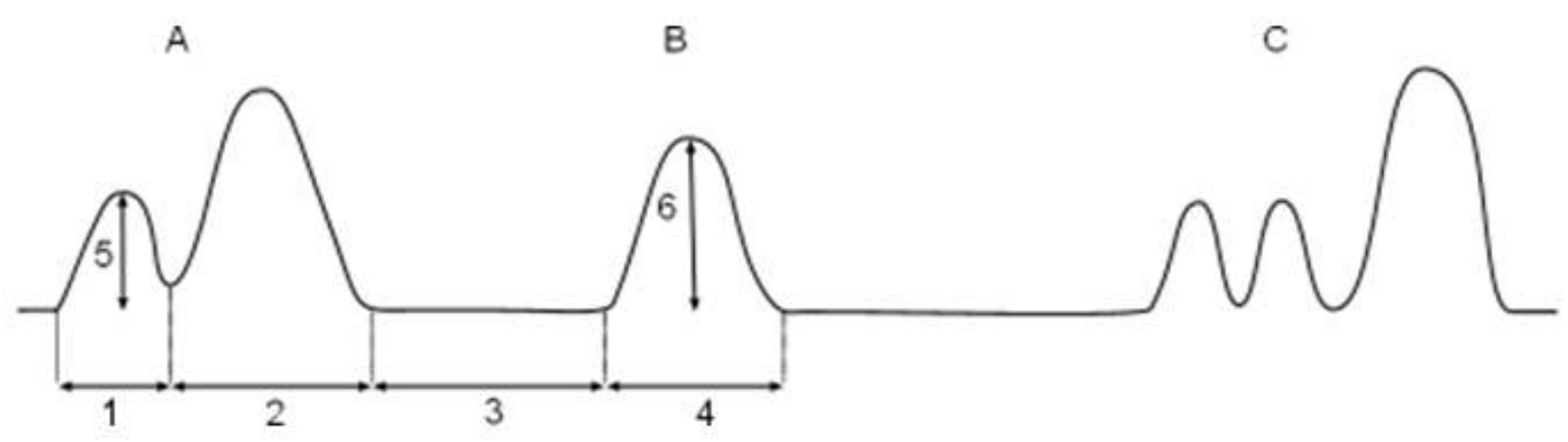

Figure 2 


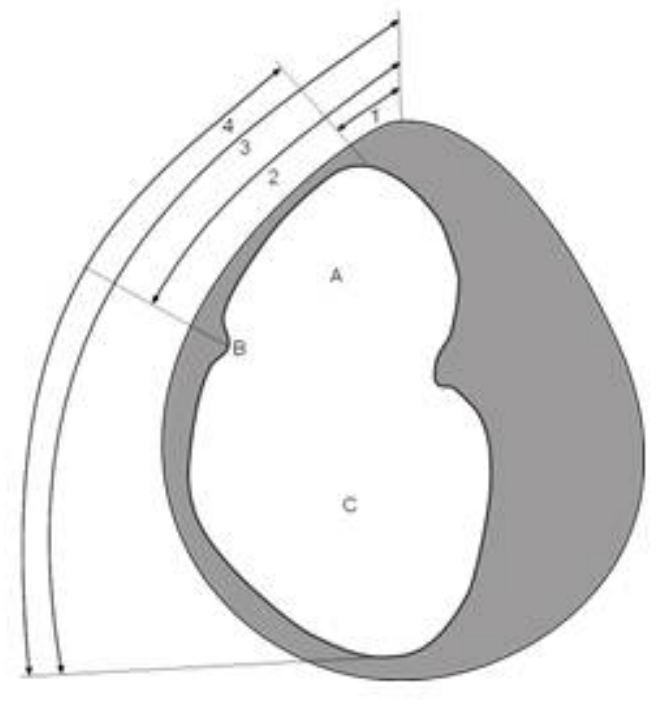

Figure 3

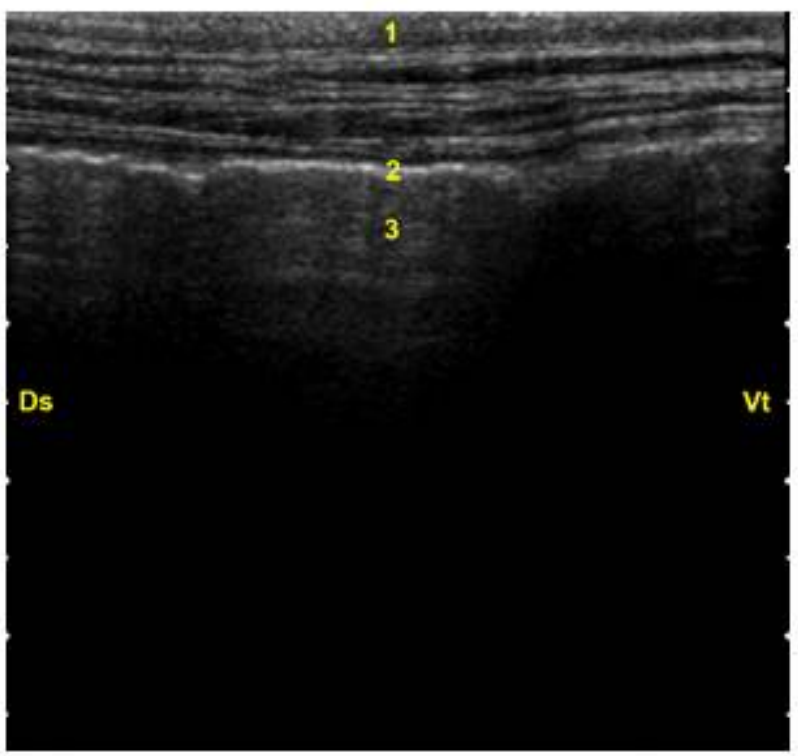

Figure 5

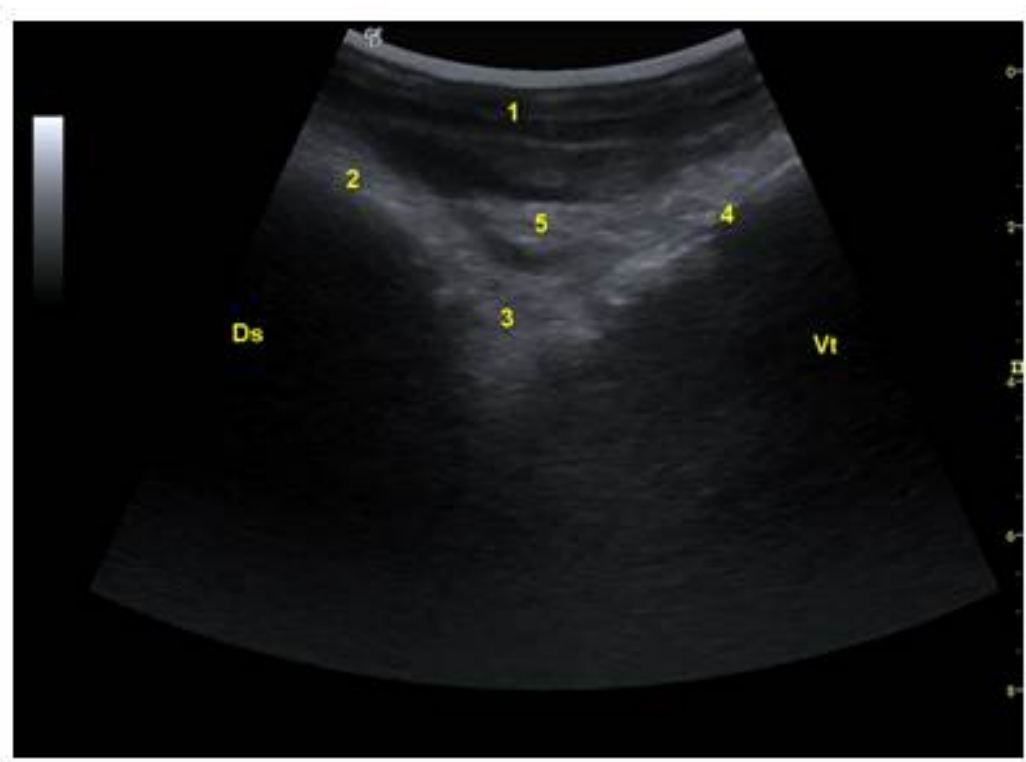

Figure 4

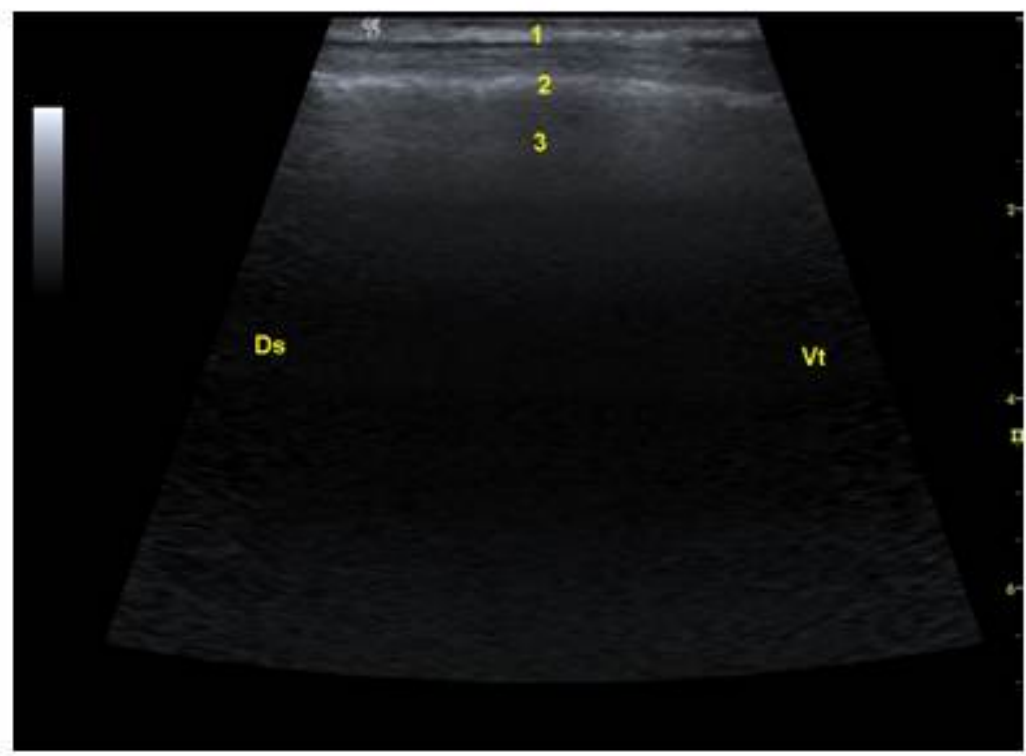

Figure 6 


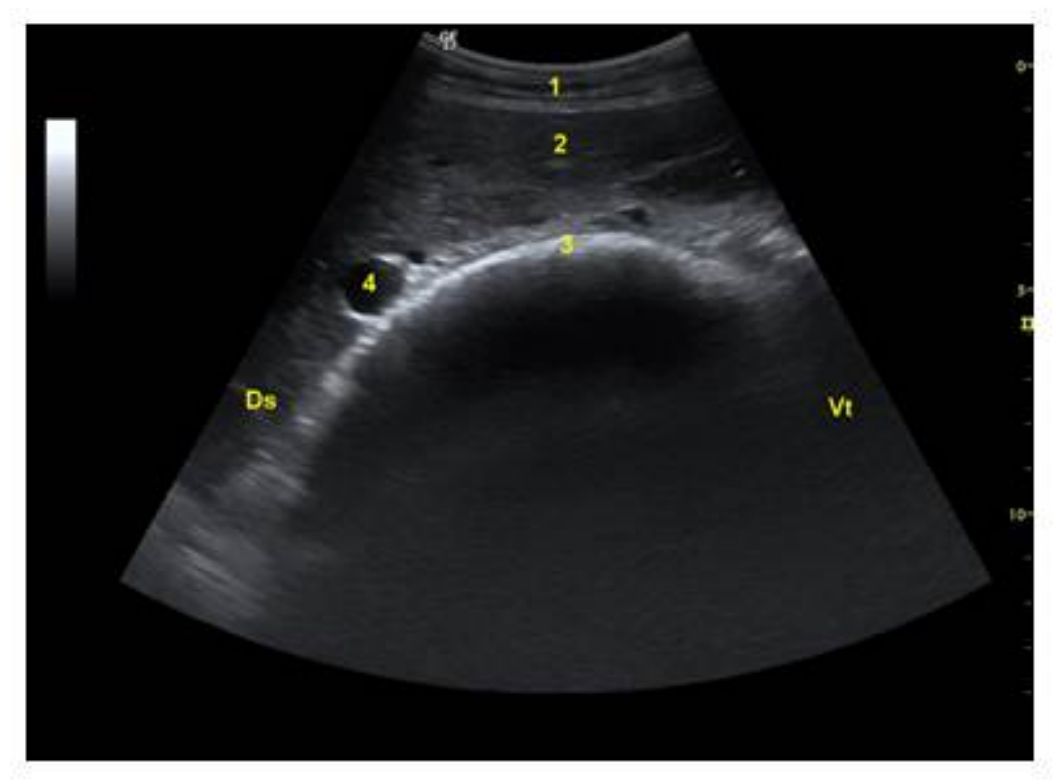

Figure 7

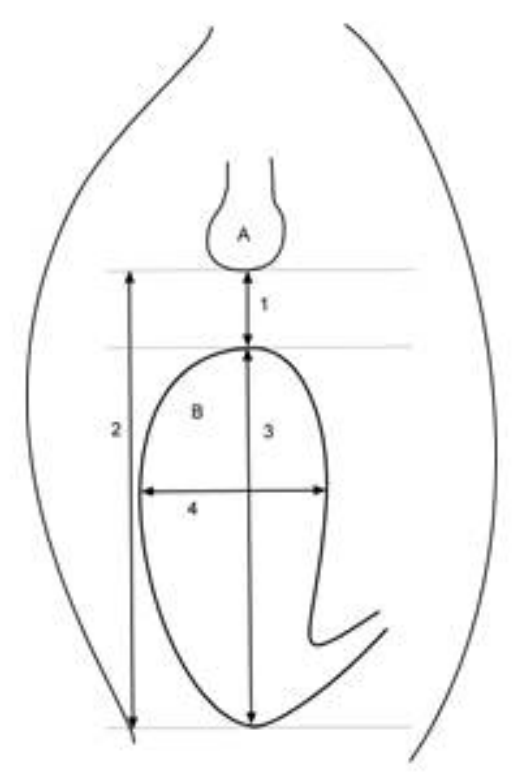

Figure 9

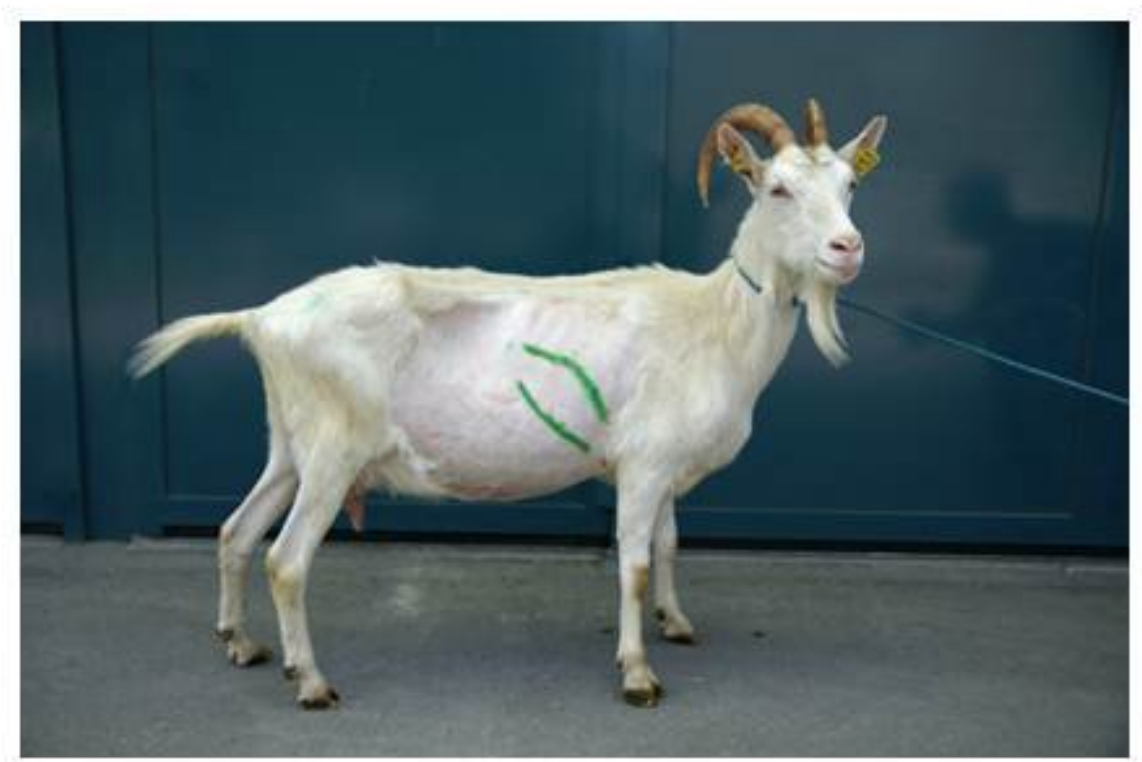

Figure 8

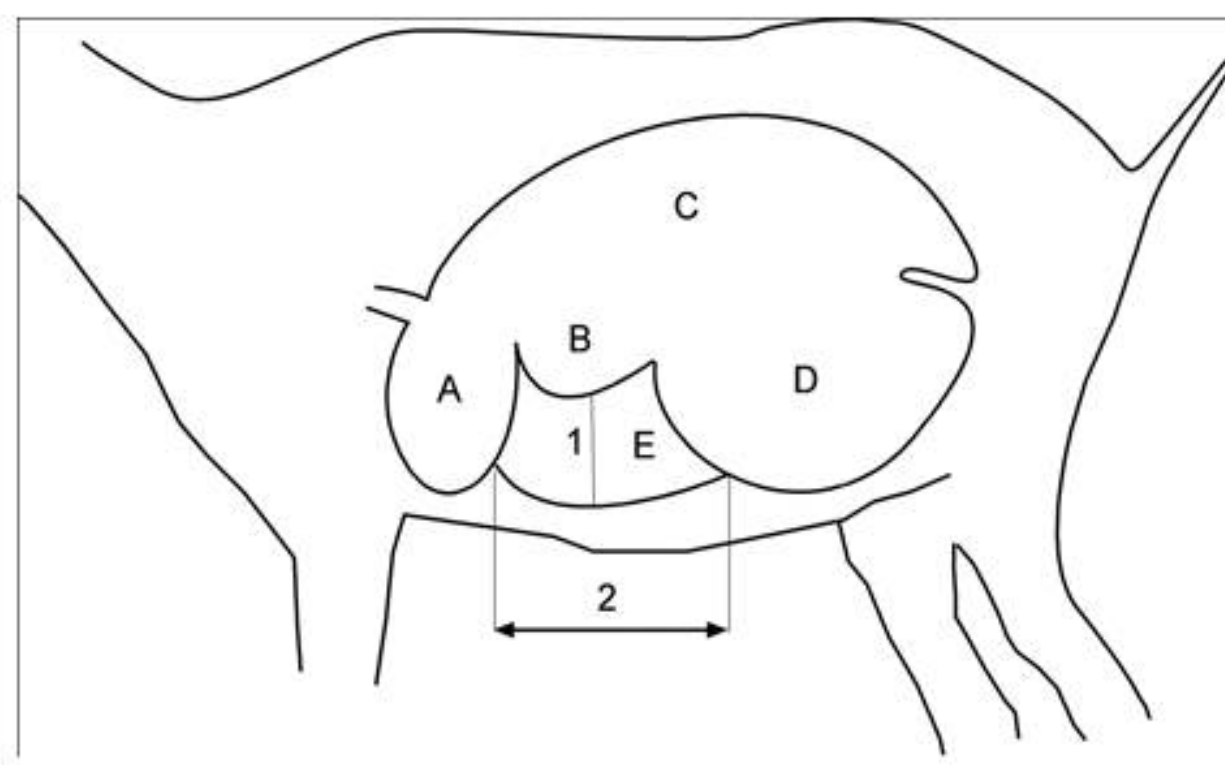

Figure 10 


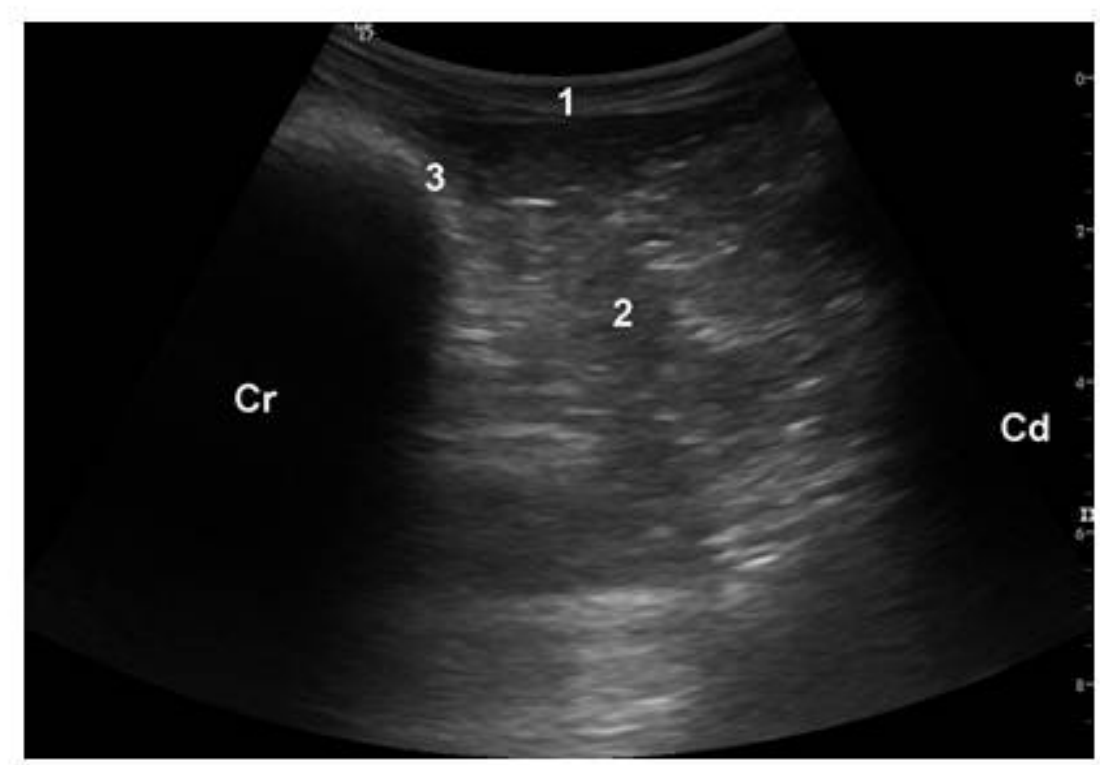

Figure 11

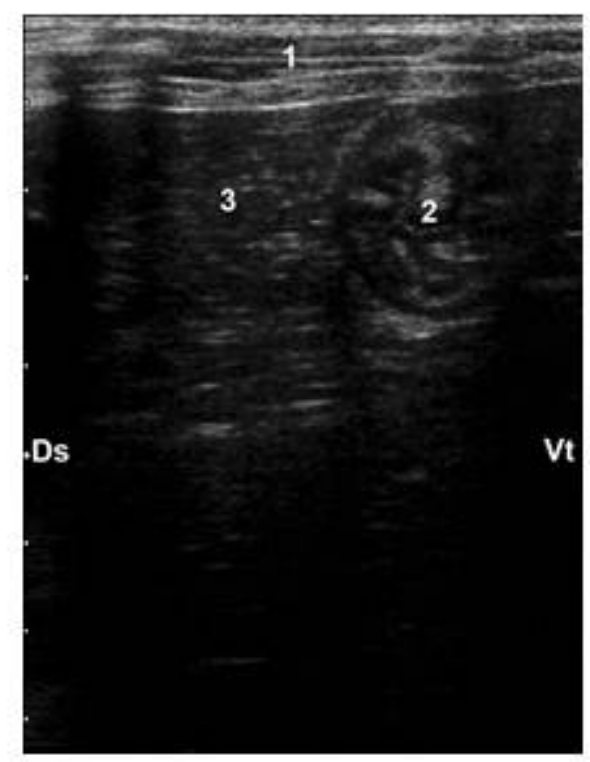

Figure 13

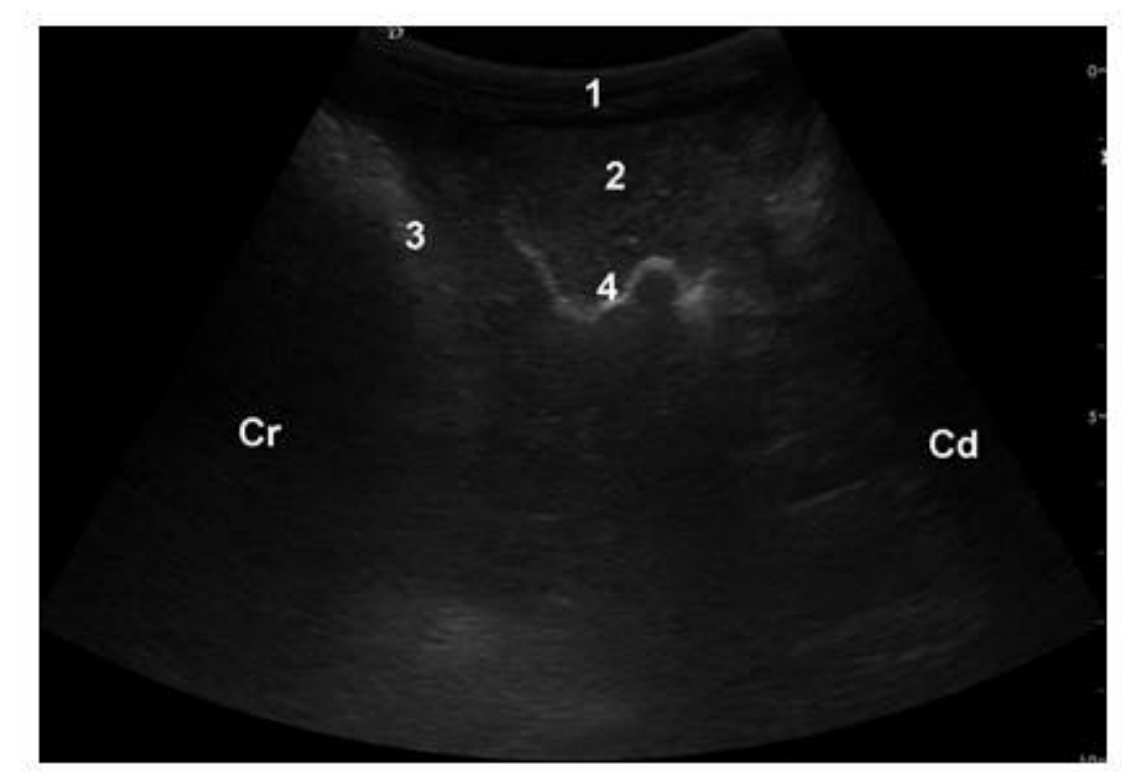

Figure 12

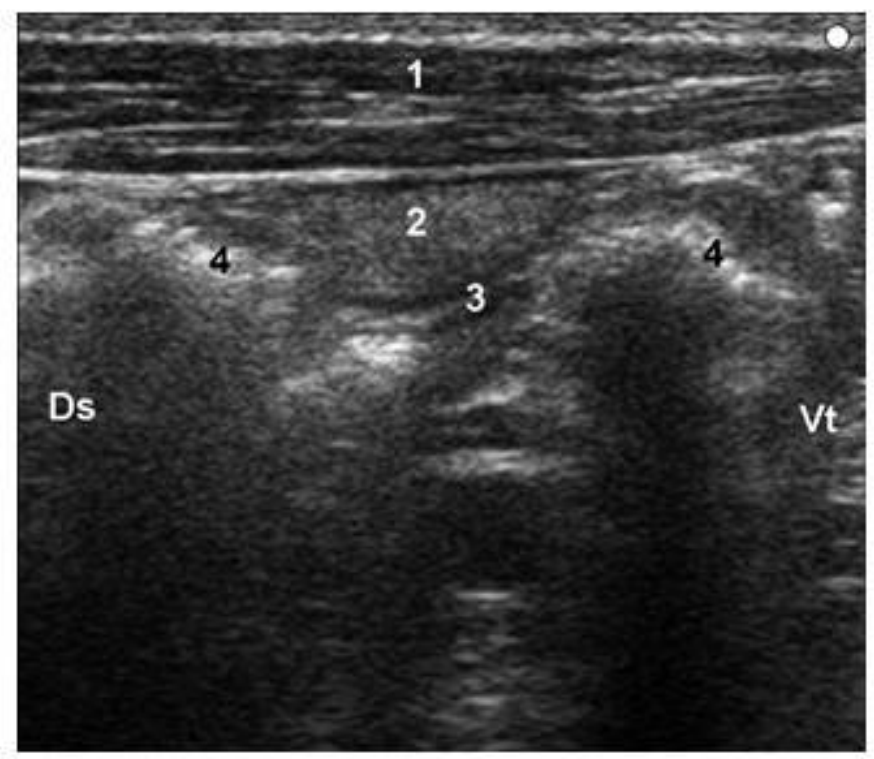

Figure 14 


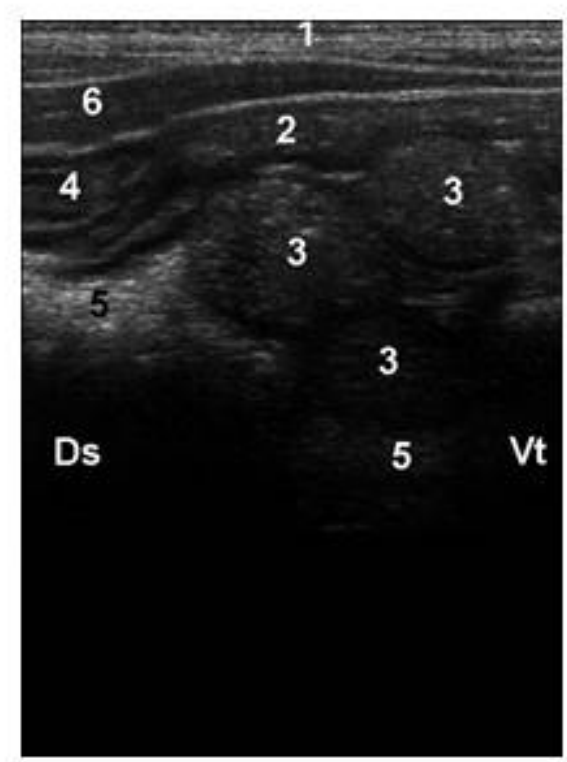

Figure 15

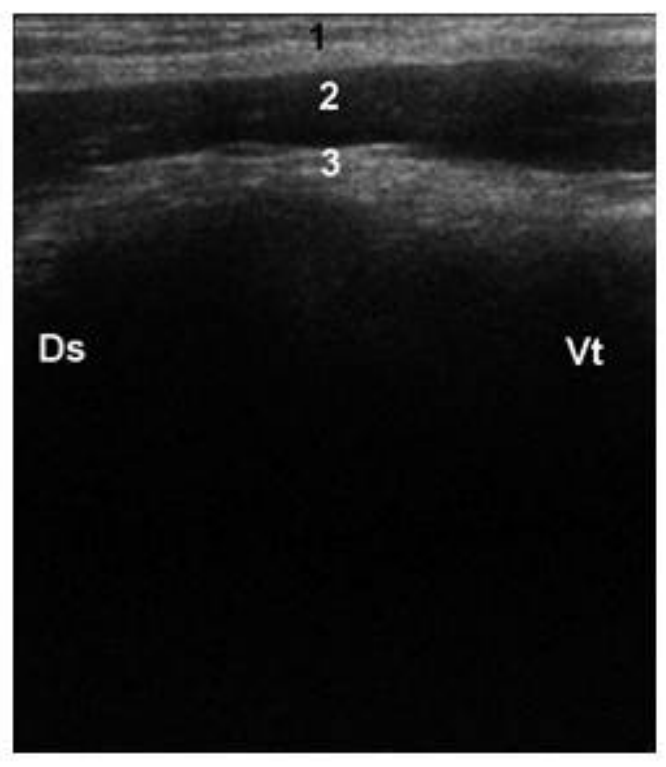

Figure 17

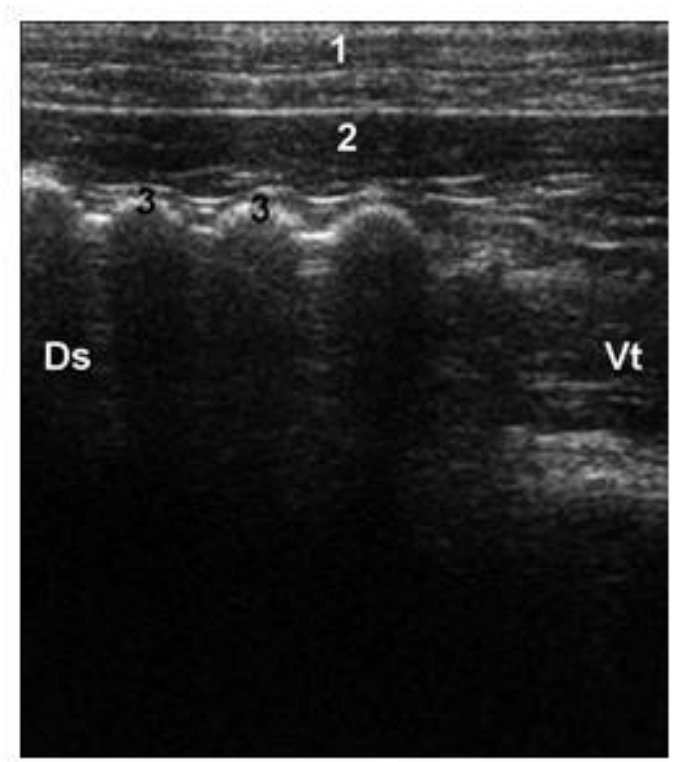

Figure 16 